\title{
Learning and Living Overseas: Exploring Factors that Influence Meaningful Learning and Assimilation: How International Students Adjust to Studying in the UK from a Socio-Cultural Perspective
}

\author{
Georgia Taylor and Nadia Ali * \\ School of Human and Health Sciences, University of Huddersfield, Huddersfield HD1 3DH, UK; \\ georgia.Taylor@hud.ac.uk \\ * Correspondence: n.ali@hud.ac.uk \\ Academic Editor: James Albright \\ Received: 28 October 2016; Accepted: 16 February 2017; Published: 1 March 2017
}

\begin{abstract}
There is a considerable amount of research investigating students' transition from college to university but it is important this focus is directed specifically towards the transition of international students, as the difficulties they face are profound. The literature surrounding international students seems to lack an in-depth understanding of how multiple contextual factors influence how students adjust to Higher Education. Therefore, the present study utilizes Bronfenbrenner's (2009) ecological theory of human development in order to understand both immediate and distal environmental influences and how they interact to impact on the individual's development from a holistic perspective. Five international students participated in a time line interview. Findings suggest that international students face a number of challenges when transitioning from their home country to study in higher education in the UK, particularly in the areas of language competence; cultural assimilation and social relationships. This in turn prevented meaningful learning occurring. Applying Bronfenbrenner's theory, the participants' broader environment was analysed, which encouraged an examination of the challenges they faced which regards to cultural influences, government influences and university policies, as well as influences from within their immediate environment.
\end{abstract}

Keywords: international students; learning; Bronfenbrenner's approach; transition; higher education; thematic analysis

\section{Introduction}

\subsection{Transition to Higher Education}

There seems to be a considerable amount of literature regarding the transition to higher education, particularly as the population of students in university is on the increase, with student numbers rising from 1,918,970 in 1999 to 2,496,645 in 2011 [1]. University life can have many challenges as students are thrown out of their comfort zone and made to face new responsibilities which often require them to develop new study habits to fit the new curriculum, re-organise their priorities, make new friends and ask for help. First year students in particular may struggle getting used to the independence that university brings, which may cause feelings of anxiety and distress. This is due to the immediate shift from the controlled environment they were once part of to an environment where students are expected to become responsible for themselves with regards to both academic and social aspects of their lives [2-5]. 
Research investigating students' expectations of university life has revealed that often their expectations are not consistent with what they experience once they are on the course, thus making transition difficult. Comparisons of students' expectations prior to enrolment and after 2 months of study revealed inconsistencies. Findings [6,7] concluded that an inaccurate perception of university life contributes towards the student disengaging from the academic and social environment, which can have unfavorable effects on their academic, personal and social development. Based on their findings the author suggested that in order for the student to form an attachment to their new academic and social environment they must eliminate their unrealistic perceptions of University life [6,7].

Although findings indicate that $80 \%$ of students manage the process of transition successfully it still means that approximately $20 \%$ of students are failing to come to terms with the academic and social demands of university life [7]. It is likely that many international students lie within this minority result, as literature comparing domestic and international students suggests that the difficulties international students face are greater than domestic students $[8,9]$. This is due to more specific challenges such as acculturative stress, language barriers, homesickness, coping with separation from friends and family and discrimination [10]. Therefore more needs to be done in universities to help support and prepare international students for their adjustment to higher education in order to minimise the challenges that they face and to ensure meaningful assessment of learning is occurring [8-10].

In terms of supporting practices the recommendation $[6,11,12]$ was to encourage the promotion of peer groups, increase staff student interaction, as well as academic preparation soon after enrolment. This supports the growing literature that argues that appropriate interventions would help students adapt, especially when adjusting to learning and assessment at degree level. For example, the practice of peer mentoring has become increasingly popular as a supporting intervention in the UK for students transitioning from college to university [11,12]. Findings reveal that mentors helped students with problems concerning orientation, course information and assessment which then helped students' bridge the gap they faced between college and university quickly and effectively [11,12].

Although there is a considerable amount of research concerning peer mentoring for university students as a whole, it would be interesting to focus specifically on how the practice influences the adjustment process of international students. It has been suggested that [6] mentoring only appears to benefit most students during the first week of university but continues to prove advantageous for the minority of students who are continuing to struggle with university [6]. Research that has examined the use of peer mentoring specifically with ethnic minorities [12] found that individual mentors and mentoring programmes are successful strategies for mentoring across racial divides. Although the area of cross-cultural mentoring has not been a major focus within the literature [12] it provides preliminary insights for further research-such as examining the practices of mentors of the same international origin paired with prospective international students.

\subsection{Rationale}

Whilst there is growing literature surrounding internationalisation in universities globally, the majority of the focus is on specific aspects of international students' adaptation, such as their social or academic experience. Without knowledge of the holistic accounts of their experience, it becomes difficult for professionals to implement supporting practices, as their attempts to improve the adjustment and learning experiences for this particular group of students may be unnecessarily disconnected $[2,3,13]$.

The present study will therefore focus on exploring the issues international students face living and learning in the UK from a broader socio-cultural context $[2,3,13,14]$. This will allow for a holistic consideration of the student experience, from the immediate influences that influence learning to macro influences that shape their learning experience. Using socio-cultural theory, broader influences on adjustment (such as culture) can be analysed as socio-cultural theorists argue that $[2,3,13,14]$ human behaviour varies by environmental context as well as proximal influences relating to the individual person. The current research will draw Bronfenbrenner's ecological framework $[2,3]$ to 
advance our understanding of how socio-cultural changes affect international students transition to HE. This particular area requires increased attention as the population of international students studying in universities in the UK is growing rapidly, and there is an escalating concern over whether appropriate and responsive levels of support is being continuously provided for international students by British Universities [10,15].

\subsection{Transition to HE for International Students}

It is important to explore the experiences of international students in order to recommend supporting practices for them. It is evident that many of the challenges they face occur in the academic setting with a particular emphasis on the students English language proficiency, as language barriers are a prominent academic issue that ultimately impede adjustment $[8,9,16]$. Language proficiency has a direct impact on how meaningful the student's learning is and can hinder student performance on assessments dramatically. For example, Liu [16] documented her own experiences regarding her struggles as an international student in Canada, stating that successful participation within the host-community was not possible due to her lack of language proficiency. She struggled to understand what her lecturers and classmates were discussing, which also prevented her from asking for help, which negatively affected her academic performance. Therefore, in the case of international students language proficiency should be central to meaningful learning and assessment.

Furthermore, various studies using a sample of East Asian international students [17] have found that they face significant challenges adjusting to western pedagogy in universities, due to the extreme cultural differences in education. Western pedagogy focuses on critical thinking and encourages discussion and debate. In contrast, East Asian students would view such behaviour as a disrespectful challenge of the instructor's knowledge. The perception in such cultures is that the student focus needs to be wholly on knowledge imparted by the teacher, due to the perception that the teacher is in power and a position of authority. This makes it difficult for international students to come to terms with the critical element of meaningful learning. The result is that they consistently avoid disagreement and conflict as they find the idea threatening and perplexing [17]. The implications of this are that meaningful assessment of learning is not possible unless the clash in perceptions regarding what constitutes an academic debate is addressed.

Another particular area that is consistently focused on throughout the literature is the role of social support on the student's adaptation, with the majority of literature focusing on quantitative studies that measure social support against various other variables. For example, Poyrazil et al. [18] conducted research with 141 international students at various universities in the U.S. The students participated in surveys measuring social support, demographic variables and acculturative stress. Findings indicated that international students with higher social support and English language proficiency experienced less acculturative stress, particularly those who developed social relationships with host nationals. However, students who socialised with non-Americans and those who originated from Asian countries experienced greater levels of acculturative stress compared with other sub groups (such as European students). Although the findings provide insight into factors that affect adjustment, the use of quantitative approaches, particularly surveys, makes it difficult to grasp the context of the student experience in-depth. Therefore, the present study will utilize a qualitative approach in order to gather rich detail from the perspective of students.

Social support predicts psychological well-being and academic performance. Lack of social support negatively affects academic outcome and causes negative psychological affect such as tension, confusion, and depression [19]. Research has found that international students have more psychological problems than domestic students do, which again emphasises the importance of recommending supporting practices for this particular group of students [20]. According to research which involved the study of African undergraduate students in an America university and Chinese postgraduate students in Singapore universities, loneliness and isolation were two of the most common psychological difficulties that international students face [21,22]. 
Finally, a common area concerning social aspects and psychological wellbeing is discrimination. The type of psychological reactions international students' exhibit reflects their country of origin. For example, international students from Asia, Central/South America and Africa report experiencing more acculturative stress than those from Europe [20,22]. Non-European international students may experience more discrimination, which may lead to lower self-esteem and depression. Salient differences such as limited language proficiency and strong accent can trigger discrimination for students who originate from Non-European countries [22,23].

\subsection{Theoretical Framework}

As briefly discussed, the present research will implement the use of socio-cultural theory to analyse the data $[2,3,14]$. Specifically, data will be analysed in relation to the proximal and distal influences identified in Bronfenbrenner's theory $[2,3]$ and the interaction between them. There is a complex link between international students' academic and social world with events within the classroom influencing events outside of the classroom and vice versa [14]. Bronfenbrenner's [2,3] ecological theory of human development was the appropriate theoretical framework to employ as it specifically examines both immediate and distal environmental influences and how they interact to impact on the individual's learning and development. Application of sociocultural theory allows us to understand influences on human development beyond the directly observable or measurable, thus allowing for a holistic consideration of the international student experience [14], which is the aim of the paper.

The theory consists of layered systems (illustrated in Appendix A, Figure A1) and stresses the interaction between the person and these structures as contexts for development. Each circle proximate to the individual denotes the environmental variables which will have an impact on development. The microsystem is the influence closest to the person and the individual is positioned at the very core of the microsystem. In the micro system the individual has direct contact with the systems and they are present in the person's immediate environment (for example, family, school, peers (and when of a certain age the workplace)). The microsystem is the most immediate influence relating to the person. Connections and interactions occur between two or more components of the microsystem, which is represented by the 'meso-system' layer. The quality and strengths of these interactions (for example the quality of the relationship between a child's family and their school) is known to have a significant developmental influence on the child/individual [2,3].

The layer that is the macro-system is composed of cultural values, traditions and laws. It refers to the overall patterns of ideology and organization that personify a given society or social group. The effects of societal values defined by the macro-system have a cascading effect on the interactions of all other systems. Due to the focus on culture this layer ties to shared identity between individuals and shared values. The theory argues that the macro system changes over time, as subsequent generations may modify the macro system leading to the person developing in a unique macro system. This is very relevant to the international student experience, as they have to move to a different place with a very different culture leading to a new macro system for the international student. The Chronosystem layer refers to the dimension of time. The outermost layer is relevant if the analysis is focussed on major transitions over the life course, as well as socio-historical circumstances. This layer, which is usually not, studied $[2,3,14]$ is very relevant as individual's re-locating, learning and living in a new country with a different culture to their own. Their experience is a major life transition and for the student a dimension of time where their environment changes and all the layers in the ecological systems theory change. 
This theory therefore acts as a useful framework for a holistic understanding of the international student experience-although addressing aspects of the whole framework is not possible in one article [14]. However, the current analysis is more comprehensive than the analysis of international post-doctoral students' experience [14], which focused solely on the Chronosystem layer. In the current analysis the exosystem layer was not analyzed (note how Figure A1, Appendix A depicts this layer but Figure A2, Appendix A does not). However, application of the microsystem, mesosystem, macrosystem and chronosystem to the data analysis will provide a more holistic understanding of direct and indirect influences on the experience of international students. This application of the ecological theory is in the Analysis and Discussion section.

\subsection{Aims}

Taking into account previous literature and the use of socio-cultural theory, the present research will therefore aim to:

(1) Explore the socio-cultural factors that influence how international students adjust to living and studying in higher education in the UK;

(2) Consideration of supporting practices which could assist international students in their transition to Higher Education.

\section{Methodology}

\subsection{Participants}

The sample of participants consisted of five students recruited on a volunteer basis who were currently studying in their third year of a degree course. The participants were recruited through the psychology research participant scheme (where students are required to participate in research in return for credits on their degree course). All those who expressed interest in the present research participated in an in-depth interview, which took place in a private room in the university library. Three participants were female and two were male, aged between 20 and 21 years old. The host-country of the participants differed, with participants originating from Bangladesh, South Korea, Nepal, Bulgaria and India. Table 1 provides an overview of the sample's composition. All participants received a participant information sheet prior to the interview. They were informed about what the interview involved and so provided informed consent. Participants were also debriefed further about how the data would be analysed in relation to the research question. The ethics committee at the university granted ethical approval.

Table 1. A table listing the five participants' country of origin.

\begin{tabular}{cc}
\hline Participant & Country of Origin \\
\hline Participant 1 (P1) & India \\
Participant 2 (P2) & Bulgaria \\
Participant 3 (P3) & South Korea \\
Participant 4 (P4) & Bangladesh \\
Participant 5 (P5) & Nepal \\
\hline
\end{tabular}

\subsection{Data Collection}

Timeline interviews (also known as snake or life history interviews) were the most appropriate method for data collection, in order to gather the participant's subjective experiences in rich detail. The timeline interview is a constructivist technique that is used to encourage reflection on critical life events that occur in the participants' personal history [24] thus proving advantageous in the present study, as participants were required to reflect on their experiences over their 3 year period of studying in higher education. The timeline interview is designed to explore peoples own perception of their 
lives as it requires the participant to create their own timeline by freely talking about their subjective experiences without any pre-determined questions being asked [25]. In contrast to using methods that include pre-determined questions the process of the participant choosing what they want to discuss enhances the personal importance of the events and gives the participant analytical power, as they are invited to participate in 'constructing the story' [26]. The flexible and unpredictable nature of the interview also contributes towards reducing research bias [27]. The timeline interview is able to gather insight into the participant's beliefs as well as insight into the particular events that may have led to the beliefs. The method achieves this by unravelling the consequential incidents that were important to the participant, and capturing how their beliefs may have changed over time [28]. In the present study the technique was used to understand how the pattern of different life events that occurred during the participant's adjustment to the new environment could be related to the wider social, historical, political and environmental context [26].

Before each interview took place the researcher explained to the participant what the research question was about, what a time line interview is and what it entailed on their part. Participants then prepared their timeline on a sheet of paper. Each participant was reminded of the nature of the research being conducted and was instructed to talk about their experiences of living and learning in a foreign country over the three-year period, starting from when they moved from their host-country up until the present time (so a linear timeline) including any positive and negative influences they may have experienced. As the method required the participant to talk freely about their experiences, pre-determined questions were not prepared. However, participants were encouraged to expand on some of the issues they raised. The researcher emphasized that there was no right or wrong way of talking through their experiences over the three-year period. Each participant was aware that the interview was being recorded and that the recordings would be transcribed. Appendix $C$ contains an example of an interview. The interviews lasted between 30 and $40 \mathrm{~min}$.

\subsection{Data Analysis}

Qualitative analysis provides an accessible and theoretically flexible approach to analysing data. The depth and flexibility of qualitative methods contribute towards the creation of an in-depth understanding of the participant's social word [29]. The underlying framework informing data analysis was a socio-cultural perspective [2,3]. Therefore the thematic analysis was theory (socio-cultural theory) driven and not data driven [29]. Application of socio-cultural theory to data analysis will provide insight into the importance of inter-psychological processes (i.e., between the person and the environment) during the participant's experience of adapting to living and studying in a foreign country. Qualitative methods and application of sociocultural theory to data analysis will therefore help to explore the influence of the participant's environment beyond the immediate situation $[2,3,14]$ from the participants unique perspective thus achieving the aim of the paper.

Data was analysed using thematic analysis following the systematic guidance provided by Braun and Clarke [29]. These steps are described below and summarized in Table A1 Appendix B. This method was appropriate as the data collected provided insight into socio-cultural influences on learning. Therefore, socio-cultural theory $[2,3]$ was appropriate to guide the thematic analysis and identify the themes within the data. Through its theoretical freedom, thematic analysis is a flexible research tool that provides a rich and detailed account of the data whilst also encouraging complexity [29]. Thematic analysis also compliments the nature of timeline interviews in that they both heavily focus on the participant's interpretation of their own personal experiences, rather than relying on the researcher's guidance and interpretation. 
Data analysis started with the researcher transcribing the data, which was also the first step to becoming familiar with the data. After transcription, the first phase of thematic analysis involves the researcher reading the transcript several times to identify initial codes. These initial codes characterise a feature of the data and can represent literal, semantic and latent content (for an example see annotated transcript in Appendix C). The procedure of coding is part of analysis, as the analyst is organising data into meaningful units [29]. However, coded data differs from the units of analysis (the themes) which are usually broader. One transcript was reviewed by both authors to ensure agreement concerning the content of the initial codes.

Identification of themes is the next phase; it is at this stage where interpretation of the data occurs. This stage is shaped by whether the themes are 'data-driven' or 'theory-driven'. If it is the former the themes will depend on the content of the data, but in the latter codes are informed by theory. As the analysis is driven by sociocultural theory codes were determined by which layer of Bronfenbrenner's framework they related to. This involved two researchers (the first author and an independent academic) specialising in the area of socio-cultural theory working together to ensure agreement on this component of the analysis. So, for example, when participants were talking about loss of friends due to moving countries the theme is 'break-up of micro-system'. Similarly when participants were talking about the importance of building new friendships in England the microsystem is of chief interest again and can be thought of as 'creating new microsystems'; both themes relate to the importance of the micro-system for assimilation in the UK. This is illustrated in the coded transcript in Appendix C. Any disagreement between the coders was resolved through discussion between the coders.

It is at this stage that any relationship between codes is noted and codes are collated to identify relationships between codes and themes. This progresses onto a consideration of the relationship between different levels of themes (e.g., main overarching themes and sub-themes within them, see Figure 1 for an example). Some initial codes may go on to form main themes (e.g., importance of making friends) whereas others may form sub-themes (e.g., barriers to making friends) and others still may be discarded or merged with other themes. This requires a re-check of individual transcripts to establish whether the themes are supported by the data (described as a level 1 check [29]) and a more complex check of all transcripts to establish whether the themes characterize important issues across the data set (described as a level 2 check [29]). An example from the current data set is initially five overarching themes were identified: the importance of social relationships, cultural differences, the importance of speaking English, differences in education and influences beyond university. However, after careful examination the theme 'cultural differences' was removed as the theme was too broad [29] in that it related to too many distinct areas. In addition to this, the process of checking themes against all transcripts (level two check outlined above) revealed this theme is discussed throughout the other four themes. Therefore rather than cultural differences being an overly broad theme the process of refinement resulted in the analysis embedding the discussion about cultural differences in relation to social relationships, education, influences beyond universityand speaking English.

The final stage is naming the overarching themes and data analysis in relation to the theme. It is this stage where analysis involves review of evidence from the research literature and interpretation involves application of theory if relevant. This stage is the analysis/discussion below. Themes are discussed in relation to the pedagogy literature and interpreted using Bronfenbrenner's ecological systems theory $[2,3]$. 


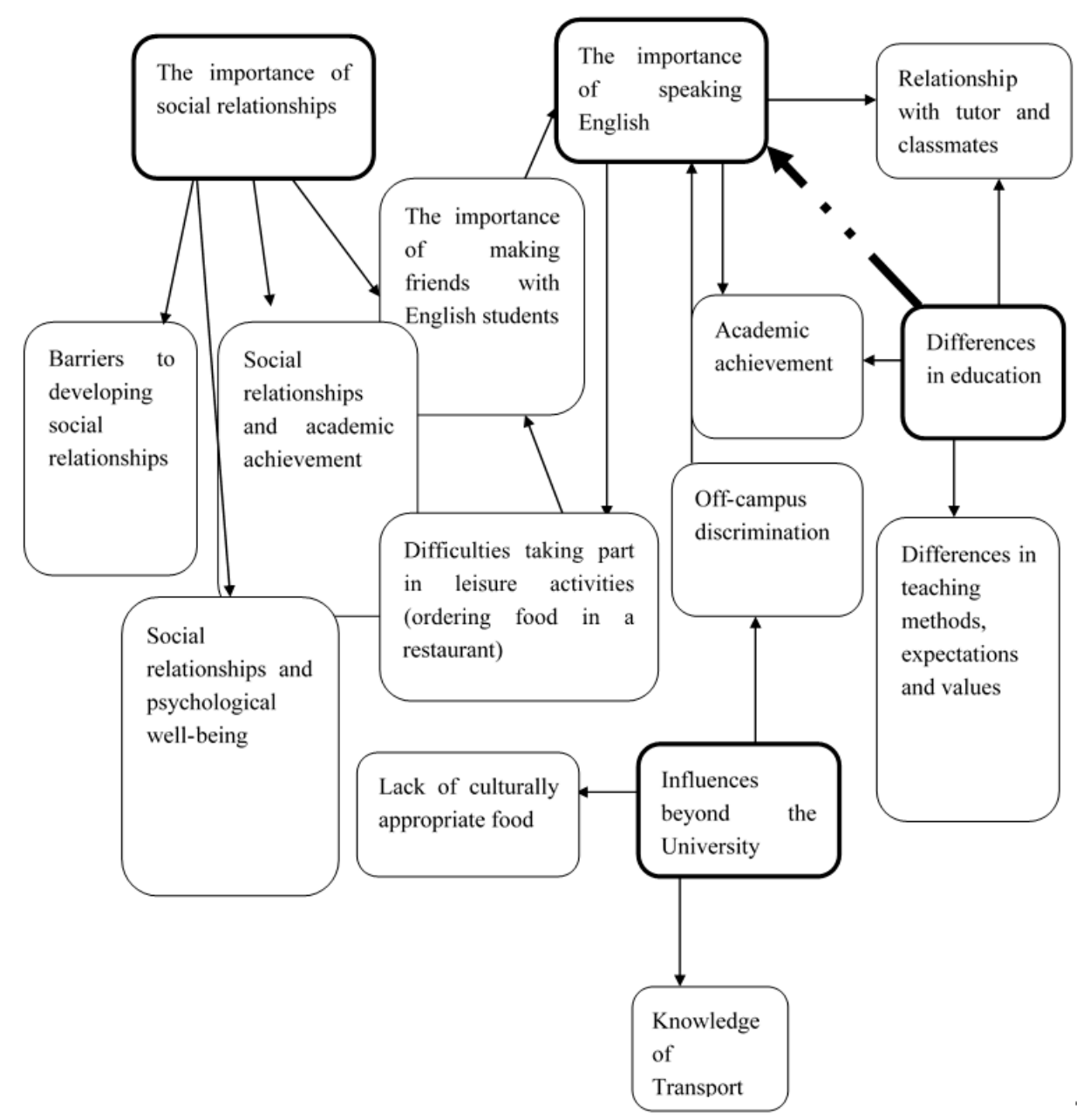

Figure 1. A diagram to show major themes and sub-themes where arrows connect sub-themes to overarching themes (depicted in bold boxes). (Note: Sub-themes can relate to other sub-themes, and more than one overarching theme. For example, the sub-theme of 'the importance of making friends with English students' relates to two over-arching themes, 'The importance of social relationships', and 'The importance of speaking English'. It also connects to the sub-theme of 'Difficulties taking part in leisure activities'. Overarching themes can also relate to each other, in our data there is only one example where the over-arching theme of 'The importance of speaking English' is connected to 'Differences in Education'. The only dashed arrow in the figure above illustrates this connection.)

\section{Results}

\subsection{Analysis/Discussion}

In order to preserve participants anonymity, they will be referred to as to as P1-P5. Their country of origin is referenced in Table 2.

Table 2. Participants' country of origin.

\begin{tabular}{cc}
\hline Participant & Country of Origin \\
\hline Participant 1 (P1) & India \\
Participant 2 (P2) & Bulgaria \\
Participant 3 (P3) & South Korea \\
Participant 4 (P4) & Bangladesh \\
Participant 5 (P5) & Nepal \\
\hline
\end{tabular}


Four overarching themes emerged from the data collected and the bold boxes in Figure 1 depict them. Figure 1 is a thematic map [29] and the footnote below the map guides interpretation of the map. The same themes are displayed in Table A1 in Appendix B. Figure A1 presents Bronfenbrenner's socio-cultural theory which is described in the theoretical framework section of the introduction. Figure A2 (Appendix A) presents the application of Bronfenbrenner's theory to the data.

\subsection{The Importance of Social Relationships}

The main theme that emerged from all five interviews was the importance of social relationships. It is evident that coping with the loss of social support, making new friends and eventually building up a new social support system is considered a major part of the adaptation process for international students $[18,30]$. From the data gathered it is clear that the first few months of arriving seem to be the most crucial time for the student and the development of their new social support system. Two of the participants, P1 and P2 both immigrated with their boyfriends, which seemed to prevent them from developing new social relationships in their first academic year. P2 stated:

I didn't want to leave my comfort zone, especially because halls were so noisy, so I stayed with my boyfriend. We didn't communicate with anyone, so at the end of year 1 hadn't spoken to anyone or anyone on my course, so I didn't have any friends at first, I was so lonely and it affected my confidence... Before if I was stressed during exam period, I could talk to my friends and it would be fine. But here I can't talk to anyone and then I get depressed and then I can't concentrate on my work and I started to miss my lectures in the first year.

Research supports the importance of social support systems on academic achievement, with findings presenting a significant relationship between a broader social support network and higher academic achievement [23]. An improved social system contributes to healthy psychological adjustment that leads to positive academic outcomes. The relationship between social relationships, stressful events and psychological well-being in the above passage is also supported by the stress buffering model [31] which proposes that individuals with social support are protected from the harmful effects that stress can cause, suggesting that social support would moderate the relationship between stressful events and psychological wellbeing [31].

It seems as though P1's social interactions with her friends from home were an important part of her life, they were an influential part of her immediate environment, and therefore they were part of her micro-system. However, since moving to the UK, the contact with her friends dissolved and the micro-system started to breakdown, which proved difficult for P1. It seems as though the only thing that had not dramatically changed in her immediate environment was the contact with her boyfriend. Although spending all her time with him provided comfort and familiarity at the time and seemed to help with her adjustment in the short term, it prevented her from building a new social support system which had negative effects on her long-term adjustment, leading to loneliness and depression.

Bronfenbrenner stresses that the individual must engage in progressively complex actions and tasks in order for development to take place. It seems as though P1 is struggling to develop in the new environment; she is not motivated to develop relationships with the students she is interacting with, both on her course and in her accommodation. Bronfenbrenner [2] proposes that "the attributes of the person most likely to shape the course of development for better or for worse, are those that induce or inhibit dynamic dispositions toward the immediate environment". This theory therefore supports the present findings as it is evident that the isolation that $\mathrm{P} 1$ is creating between herself and the environment is delaying the development of her social system, which hinders her adaptation by causing depression and negatively affects her learning and academic involvement.

It is also interesting to note that unlike P1 and P2, P4 had contact with his roommate who had lived in Huddersfield for a year, prior to arriving to Huddersfield. This immediate social bond P4 developed with a student who was familiar with the area and culture seemed to ease his transition, 
and gave him the confidence to develop various different social systems and build up important micro-systems, allowing P4 to settle in a lot quicker than the other participants. P4 stated:

The first day was really tough, it was very over whelming, and I was traumatised. I went to bed straight away. But the next morning I woke up it started to get better, my house mate let me borrow his phone to ring my family and then he came into town with me, showed me around and helped me find a job... I met lots of friends from my job and it gave me more confidence, and then we went out and I met more friends from different places.

According to Bronfenbrenner, the most common transition experience involves modification of the meso-systems, as old micro-systems breakdown and new ones emerge. The interplay between $\mathrm{P} 4$ 's new micro-systems is revealed in the above passage, as P4's social network in work helped him create further social systems when they went out. The broad social network P4 developed therefore increased his confidence and helped him socially adjust to the new environment.

Participants also discussed the importance of forming social relationships specifically with people from English culture, which supports the research outlined in the introduction. P1, P2 and P3 all stated how important it was for them to make friends from the UK, in order to learn more about the culture and improve their English language proficiency. P2 stated:

I wanted to understand their mentality; it was so different to Bulgarians. I wanted to be friends with them so I could understand how they think, their views, their beliefs, their traditions and I thought maybe this would help me, and it did...I realised that it's not polite to talk about politics here, but that's all we talk about at home, so now I learnt how to 'small talk'.

It seems that the students eventually developed new micro-systems over time, through effective participation within the new social environment. The macro-system influences the nature of the development of these different social relationships, due to the differences in socially accepted values and beliefs within the different cultures. As the students began to develop relationships with individuals from the host culture, their experiences started to become more positive, and as they became more confident with the new culture they began to socially adjust to their new environment. P2 stated:

I started to speak to people. I made a best friend from England who always helped me and took me to places and I wasn't afraid to try different words or phrases because I knew if I messed up she wouldn't laugh, she would just say you don't say that here.

Societal acceptance is one of the most common needs for international students. Findings suggest that for students to adjust in their new environment they need to develop a degree of social competence in the new language, feel respected and accepted [22]. P3 also powerfully illustrated the macro-system influence in her desire to conform to the social norms of English culture, in order to be accepted by her English peers. P3 stated:

In Korea, University girls put on high heels everyday but British girls they only wear flat shoes. People started to ask why you wear these shoes every day, and they thought it was weird, so I started to wear flat shoes too.

This finding supports research that suggests that international students must change their behaviour and adopt the ritualized routines of the host country so they can successfully become part of the community and develop a shared identity with host nationals [32]. It is evident from the data gathered that international students who immediately build up a social support system adjust to the new environment quicker than those who do not, which emphasises how important the first few months following their arrival are for their social and academic development as well as their well-being. Although the University the research was conducted at offers students the opportunity to meet other 
students from the same nationality through different societies, it seems as though developing social relationships with the host-culture is equally important in order for them to learn more about the new culture they are living in, to ease their adaptation.

\subsection{The Importance of Speaking English}

The ability to speak English also seems to be a significant factor in the student's adaptation. It seems as though the students who have greater fluency in English language experience greater opportunities that can help create a smoother adaptation, conversely those who are less fluent seem to struggle. This finding strongly supports research discussed in the literature review. Immediately, from an ecological perspective, the importance of speaking English is a macro system influence, as the government proposes that the individual must achieve a certain IELT score on the English entry test, in order to study in higher education in the UK. However, many universities including this one offer students the opportunity to attend an English course prior to starting at University if they do not achieve their IELT English score, which depending on whether they pass, permits their entry to the University. All the participants passed their IELTS English test except P3. However, she gained entry through the university English course. Although this opportunity may have seemed like it enabled P3's learning, an inability to speak English fluently resulted in various issues which ultimately disabled her adaptation and learning. P3 stated:

I was very clever in Korea but now I feel stupid because I don't understand everything as well as everyone else in my class, because I do not speak their language, and I struggle. My grades were not very good in first year.

The effect of language differences is a macro-system influence that hinders P3's academic performance. Although P3 was highly ranked academically in Korea, she did not develop the language requirements necessary to be high achieving in the UK, particularly in the first year. Research supports this point; students who were successful in their home countries may find it distressing when they cannot express their academic ability in English as well [19]. In comparison to the other students who were almost fluent in English P3 struggled to understand her classmates during group work, therefore never made much of a contribution, which isolated her from her peers and prevented the development of social relationships. P3 stated:

In my first year I was really timid in class, especially when we did group work. English is so difficult because even though I can understand and I thought about what grammar is incorrect and correct, when you actually try to communicate in English you don't have enough time to think and work out what the person is saying so it becomes hard to communicate.

Again this macro-system influence seems to create yet another barrier for P3 in terms of developing social relationships and interacting with her English peers (as discussed in theme 1), which then negatively affected her academic development. Although the practise of group work may be valued at university level and it can enhance learning through interaction and sharing ideas, it seems as though it disables learning for international students as they become isolated within their group, due to their lack of competence in speaking the host language. Findings reveal that international students perform higher in some academic classes when they have greater English language proficiency, as they feel more comfortable speaking in class and taking part in discussions [33,34]. P3 also stated that she felt as though she was unable to ask her tutor for help due to the language barrier.

I was scared to ask my tutor for help because I thought that he wouldn't be able to understand me and I wouldn't be able to understand him and I was scared the he might think I'm stupid, and the work was really hard, especially because I did it alone.

Important meso-systems that P3 seemed to value in her own country (such as the interaction with peers in class and the relationship with her tutor) were no longer present in her new environment. 
This was especially the case in the first year, which negatively affected her academic development, as effective participation within the academic environment was not regularly exhibited. This finding stresses the importance of speaking English in order to feel supported academically, which in turn improves learning and performance on assessments. It was important for P3 to make English friends so that she could become more fluent; however, her inability to communicate stopped her from developing this important micro-system. P3 stated:

I really wish to have lots of English friend to improve my language but it's hard to spend time together when they don't understand me speaking.

Not only did P3's lack of English disable her learning and cause a barrier to forming social relationships with English students, it caused her to have trouble with completing daily tasks, which prevented her from effectively participating in the new environment-thus hindering her development and adaptation. P3 stated:

I didn't really go out because I was scared of how to ask for things. I remember when I first came and I went to a restaurant and I ordered steak, fillet steak, and they didn't understand me so I had to write it down. I have to write everything down wherever I go. People often get angry or laugh and mock my accent, so it put me off going out unless I really needed to for a while.

It is also evident from the above passage that $\mathrm{P} 3$ experienced serious discrimination due to her lack of English, which stopped her from going out thus hindering her adaptation. Discrimination is a macro-system influence resulting from lack of understanding between different cultures, ethnic groupings and lack of shared national identity. It is interesting to note that P3 was the only participant to report such serious discrimination when attempting to communicate with others. It seems as though there may be a relationship between fluency in the host-language and discrimination [34]. There is a reciprocal relationship between discrimination and communication barriers, whereby international students who struggle with the host-language experience discourtesy, a refusal to speak, or aggressive hostility. Findings suggested that once the native speaker has made a quick judgment on the inadequacy of the student's language, they began to show indifference and disrespect [34].

\subsection{Influences Beyond the University}

All five participants experienced influences beyond the University that played a major role in their adaptation. For example, P3 stated:

When I feel tired or ill we usually eat a certain soup and rice but here I cannot buy it or any

Korean stuff so I ate hamburger, this makes me feel really sad and homesick.

The cultural differences in food have an impact on P3's psychological well-being, which ultimately affects her adaptation, as she is unable to feel a sense of familiarity. Food from the student's home country can provide a sense of comfort since each culture and country is characterised by their own foods-particularly when the student is missing home and struggling with homesickness [35]. Although the issue may not strike as particularly important at first, research suggests that the food students eat is extremely important to them both emotionally and physically and is considered one aspect of student life that is least open to change [36]. International students form an emotional attachment to home food as they positively associate its familiar taste to nostalgic thoughts of home and belonging. Therefore, the lack of access to their familiar food can create feelings of homesickness [37].

According socio-cultural theory, the absence of culturally appropriate food can act as a barrier to developing important micro-systems. For example, for P3, eating out was an important social activity at home that was not happening in the new country. The inability to re-build this important micro-system that once existed at home is therefore causing difficulties in terms of her adjustment to 
the new environment, as it is a barrier towards her effectively participating within the new community. P3 stated:

In Korea, going out for food was our main social activity, we would always meet up for food or even if we went for a drink, we would order soup and fruit, we sit there, and everyone talks. But I don't really like the food here so we don't go out much and there's not really much else to do, I miss it.

In her third year P3 started to meet new people, which re-built important micro-systems, which in turn improved her assimilation. This made her feel more at home and reduced the cultural shock gap she felt as this group introduced her to Manchester-a place where she could explore new ethnic restaurants and eat her home food thus providing a similar cultural food experience as her home country. Larger cities in the UK such as Manchester provide for a much more diverse population in comparison to smaller towns, which do not have a range of outlets for differing cultural cuisine. P3 stated:

Manchester really helps when I'm homesick, I go to the restaurants and eat my home food with my friends and I feel better.

Furthermore, all five participants stated how they found the differences in currency extremely difficult to get used to, which caused a lot of frustration and unnecessary problems. P1 stated:

I had a lot of issues with managing money in my first year because the currency was so different, so if it was $£ 1$ here it was 100 in Indian currency. I just thought, oh it's only 1 it's so cheap and this was a real problem for me because I ended up spending far too much.

All five participants experienced difficulty understanding currency and the monetary value of items. This resulted in them spending too much. This proved to be extremely problematic, particularly for students who were trying to become financially independent for the first time. P5 stated:

The first time I did my food shop I spent that much money that I had to walk to uni for the rest of the month because I couldn't afford the bus. I felt like we had no help, and these things are hard to figure out on your own. I never did a food shop at home never mind in a different country with different money.

Furthermore, all participants stated that they had trouble with finding their way around the area and getting used to the different transportation system, particularly in the first few weeks. P4 stated:

When I arrived in the UK I got a taxi from Manchester airport to Huddersfield which cost me $£ 80$. I had no idea you could get the train. I had no idea I was meant to. I was so annoyed.

According to Bronfenbrenner's model, transportation systems are an exo-system influence. However, as it is the participant's lack of knowledge of how public transport works, this issue can be interpreted as a micro-system issue as they do not have an appropriate social group in place to inform them of such things. The lack of knowledge about the new transportation systems again caused unnecessary problems and frustration, which could easily be prevented through the provision of information about the different travel options available.

\subsection{Differences in Education}

One of the biggest changes for international students is the transition to a new educational system-from their home to the host-country. Research suggests that learning styles are culturally bound [38], which supports the present findings which reveal students struggle adapting to cultural differences in education, particularly the students from East Asia (South Korea). For example, P3 stated: 
In Korea, students always say 'teacher' before we ask a question, we always respect our teacher. But when I say teacher when I have a question here, other people start to laugh at me. I thought a student shouting out was very rude, but for British people its normal. I find it hard to ask questions this way, so I prefer to stay quiet...In Korea if we get the answer wrong it's really bad, but in UK class British people just shout out even when they don't know the right answer. I found that we had to investigate and discuss the answers ourselves and this was hard, I struggled with my work because I did not want to ask.

This is a huge macro-system influence that is disabling P3's learning as she is finding it difficult to adjust to the new teaching methods, expectations and values. This prevents her from asking questions and discussing answers due to the fear of being wrong. This finding therefore supports research previously discussed in the literature review, which claims that learners from places such as Korea find the western ways of teaching and learning culturally inappropriate [39]. The majority of East Asian students [15] often view the unfamiliar debating styles-where the lecturers and students share their views and opinions, which are open to critique and challenge-as threatening and confusing. P3 further stated:

I prefer the teaching methods at home, I felt more supported. I knew whether I was right or wrong because [the] teacher told us.

The educational environment, i.e., teacher-student interaction, social support and interaction within the seminars is an important meso-system. It is evident that there is a negative shift in P3's meso-systems, due to the transitional shift in education. She comments on this difference:

I felt extremely out of my comfort zone in the lecture halls I would never ever ask a question in front of all those people because of my language, and their language and the lecturer seemed like this really scary, really important figure of authority. It wasn't like in Bulgaria, learning felt a lot more casual at home and I could just go to the desk and ask my question, but it felt scary and so unfamiliar here.

Instead, P3 seems to be distancing herself from new ways of learning which prevents her from developing the important educational micro-systems she had in her home country. However, despite the cultural differences in learning it seems as though the students adapted to new educational expectations, values and teaching methods by the time they reached their third year-which shows that although the adaptation process may be slow, they are not completely reluctant to change. Although East Asian students prefer a much more teacher-centred learning style where they are 'spoon fed' rather than exploring their own answers, they are capable of adapting their learning styles, so they are able to pick up new teaching methods and learning strategies with time [38]. P3 stated:

I've learnt how to discuss my answers. I like discussing the answers with my class mates, I realised that it's okay to be wrong here.

However, in the UK most degree courses are over a three year period. Therefore, a lot more needs to be done to ensure students adapt to the transition sooner. Below we make recommendations based on our findings to assist HEI's.

\section{Conclusions}

It is evident that the ability to function effectively in the new environment is dependent on distal and proximal influences that interact to shape how international students adjust to living and learning in the UK. Adopting an ecological perspective of transition to Higher Education and learning in a new environment allowed for an examination of how the environmental context and culture shape the international student experience. Based on our analysis some recommendations are suggested to ensure the student receives assistance in areas beyond their academic needs (e.g., assistance concerning transport system and currency translation). However, these practices are only recommendations and 
so should be investigated and adapted according to the Higher Education setting. For example, in the South culturally appropriate food may be plentiful but it may be that a more careful consideration of currency is needed as the North South Divide in the UK means that it is much more expensive to live in the South.

Overall, in alignment with previous research, it is clear that international students face a number of challenges when transitioning from their home country to study in university in the UK; particularly concerning language, culture, and social relationships. Using Bronfenbrenner's ecological theory of human development, the participants' broader environment was explored, which encouraged the examination of cultural influences, government influences and university policies, as well as influences from within their immediate environment; such as their social support system and university lectures/seminars, interaction.

From the data, it is apparent that in order for the student to participate effectively within both their social and academic environments they need to build up a new social support system. As discussed in the analysis, the earlier the student starts to develop new social relationships, the smoother their adjustment to the new environment becomes, particularly if they develop relationships with individuals from the host-country. This encourages them to learn more about the culture, area and language, which helps them participate effectively in both their social and academic environment. However, this recommendation needs to be considered in line with the discrimination students' experience.

Although the sample of participants originated from various different countries, it was clear that the student from South Korea experienced an increased amount of challenges, which supports previous literature discussed in the literature review suggesting that the difficulties East Asian international students face are profound. In the present study, this finding particularly relates to lack of English language proficiency and the extreme differences in culture, particularly in education. However, it is evident that students from different areas still experience multiple challenges and it remains important to study a variety of individuals of different ethnicities, as they all faced unique problems.

Overall, application of socio-cultural theory to analyse international students' transition to Higher Education allowed for a holistic consideration of the multiple challenges they face and what can be done to help reduce these challenges. The results of this study continue to reinforce the value of applying a socio-cultural perspective to analyse transition in education in order to understand the well-being of students in their new community. The findings underpin the importance of acknowledging that the students' ability to adjust to the new environment is not only determined by the individuals themselves but also by various features of their physical and social context. It would be interesting for further research to explore this topic further and to investigate whether environmental influences differ within different areas of the UK. For example, as Huddersfield University is situated in a small town, it would be compelling to explore whether universities in London-which are situated in a much larger and busier environment and provide for a much more culturally diverse population-present different influences in comparison to the present study.

\section{Recommendations}

In order to address the students' need for social support from the host-culture (theme 1 'the importance of social relationships') a buddy system could be implemented where international students are matched with a student who has been studying in the UK and has knowledge about the area and culture. The buddy system would also prove advantageous for students who may not have the confidence to join a society as soon as they arrive, or those who tend to isolate themselves, as seen with P1 and P2. This system is also supported by research findings which suggest that the interaction between international students and the host culture will also give English students the opportunity to increase their awareness of diversity, which will hopefully encourage their acceptance and tolerance towards students from various different ethnic/racial backgrounds [12,17]. 
The recommendation starts the same for theme 2 'the importance of speaking English'. Again, the findings for this theme support the suggestion of creating a buddy system to ease the student's adaptation, by encouraging the development of social relationships with English students. The system will allow students to develop their English language and understanding of English culture, which will ultimately provide greater learning opportunities and give students the confidence they need to take part in daily tasks. In addition to this meaningful assistance can be provided by tutors if they explicitly invite international students for discussions about their learning experience. If offered by the tutor to the student it may reduce the inhibition of seeking help on the student's part. If the tutor is aware of difficulties, they could set up a plan to improve the student's development. The crucial element seems to be difficulty approaching teachers for help so further pro-activeness on the part of the institution is needed. This problem is not unique to international students. Research in the area of pedagogy reveals that students do not feel comfortable approaching teachers to clarify feedback on their learning [26]. Therefore, a more pro-active approach is needed in this area for both home and international students.

The recommendation for theme 3 'Influences beyond the university' is to produce simple information packs relating to each identified issue. Although food, money, and transport are all influences beyond the university, they are consistently producing problems for international students. Therefore, the university should provide an information pack advising on major influences beyond the university such as ways to travel, different places to eat and information on the new currency, which will decrease the number of stressors that international students face and help them develop a sense of belonging within the new community. Furthermore, it might also be useful for the students if they had the opportunity to speak to previous international students in order to gain a more realistic account of what to expect and how to prepare for situations, such as finding appropriate transport prior to their arrival.

The recommendation for theme 4 'differences in education' is to educate lecturers so they are aware of cultural differences in teaching and learning, particularly regarding students from East Asian countries, as their values and expectations conflict with those in more Western countries. The more aware teachers are aware of the cultural differences in learning, the more they can accommodate the needs of international students, which will ease their adaptation academically and contribute to an increase in their academic performance. As discussed in the analysis section, students' learning methods and styles are different due to cultural differences between education systems in different countries. Therefore, universities could also think about introducing a social support group at the beginning of the students first year, specifically with the aim of sharing information about educational style in countries like England.

Overall, it seems as though universities could put more practices in place in order to make the student feel a sense of belonging within the new academic environment as well as being fully prepared for what it entails. With further supporting practices implemented the feelings of intimidation will decrease which will allow students to adapt through increasing their academic engagement and thus performance. We have made some recommendations that may help support international students in higher education across the UK and possibly more widely.

Author Contributions: Georgia Taylor conceived and designed the study, collected and analysed the data. Nadia Ali carried out data analysis and did the work necessary to write up the paper for publication.

Conflicts of Interest: The authors declare no conflict of interest.

\section{Appendix A}

Figure A1 depicts the layers of Bronfenbrenner's theory which was the theory used to analyse our data. 


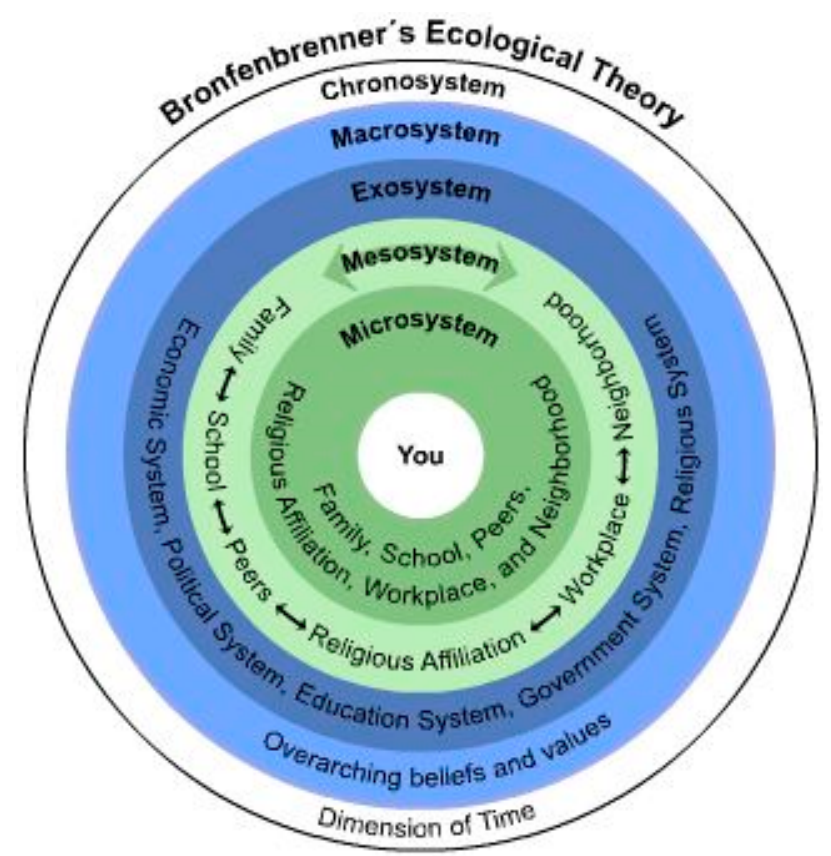

Figure A1. A diagram to show the different systems in Bronfenbrenner's ecological systems theory.

Figure A2 is annotated with the data from our study.

Chronosystem-student transitions from home country to study in the UK thus changing all the layers in the ecological systems theory, depicted below.

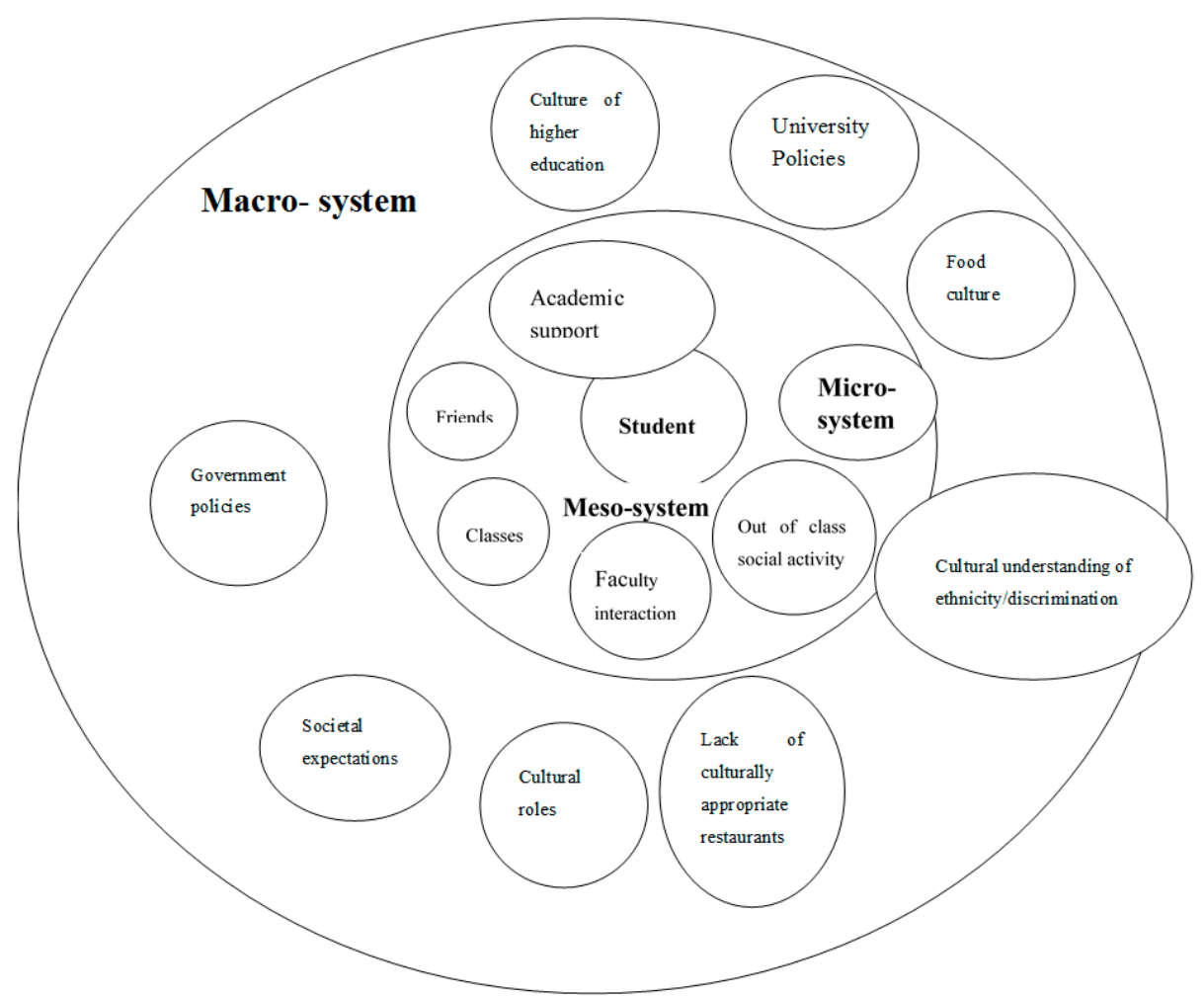

Figure A2. Transition to UK Higher Education. A diagram to show the application of Bronfenbrenner's (1979) theory to our data. 
This diagram depicts some of the issues international students experienced living and learning overseas. Each issue is depicted in the relevant layer of the ecological systems theory and is described in the theoretical framework outlined in the introduction. For example, friends are categorized as being part of the micro-system whereas experience of discrimination is a macro influence. The impact each experience had on the students' ability to assimilate to living and learning in the UK is discussed in the analysis/discussion section of the paper.

\section{Appendix B}

Table A1. Stages of Thematic Analysis.

\begin{tabular}{ll}
\hline Phase & Description of the Process \\
\hline $\begin{array}{l}\text { 1. Familiarising yourself } \\
\text { with your data: }\end{array}$ & $\begin{array}{l}\text { Transcribing data (if necessary), reading and re-reading the data, noting down } \\
\text { initial ideas. }\end{array}$ \\
\hline 2. Generating initial codes: & $\begin{array}{l}\text { Coding interesting features of the data in a systematic fashion across the entire } \\
\text { data set, collating data relevant to each code. }\end{array}$ \\
\hline 3. Searching for themes: & $\begin{array}{l}\text { Collating codes into potential themes, gathering all data relevant to each } \\
\text { potential theme. }\end{array}$ \\
\hline $\begin{array}{l}\text { 4. Reviewing themes: } \\
\text { 5. Defining and } \\
\text { naming themes: }\end{array}$ & $\begin{array}{l}\text { Checking in the themes work in relation to the coded extracts (Level 1) and the } \\
\text { entire data set (Level 2), generating a thematic 'map' of the analysis. }\end{array}$ \\
\hline 6. Producing the report: & $\begin{array}{l}\text { Ongoing analysis to refine the specifics of each theme, and the overall story the } \\
\text { analysis tells; generating clear definitions and names for each theme. }\end{array}$ \\
\hline
\end{tabular}

Table A2. Classification of themes.

\begin{tabular}{|c|c|c|c|}
\hline $\begin{array}{l}\text { a. The importance of Social } \\
\text { Relationships }\end{array}$ & $\begin{array}{l}a^{1} \text { The importance of } \\
\text { Speaking English }\end{array}$ & $\begin{array}{l}a^{2} \text { Differences in } \\
\text { Education }\end{array}$ & $\begin{array}{l}\text { a. Influences beyond } \\
\text { the University }\end{array}$ \\
\hline (b) Barriers to developing & $\begin{array}{l}\text { (c) Academic } \\
\text { achievement }\end{array}$ & $\begin{array}{l}\text { (c) Relationship with } \\
\text { tutor and classmates }\end{array}$ & $\begin{array}{l}\text { (b) Lack of culturally } \\
\text { appropriate food }\end{array}$ \\
\hline $\begin{array}{l}\text { (b) Social relationships \& } \\
\text { academic achievement }\end{array}$ & $\begin{array}{l}\text { (b) Off-campus } \\
\text { discrimination }\end{array}$ & $\begin{array}{l}\text { (c) Academic } \\
\text { achievement }\end{array}$ & $\begin{array}{l}\text { (b) Knowledge of } \\
\text { transport }\end{array}$ \\
\hline $\begin{array}{l}\text { (b) Social relationships \& } \\
\text { psychological wellbeing }\end{array}$ & $\begin{array}{l}\text { (c) Relationship with } \\
\text { tutor and classmates }\end{array}$ & $\begin{array}{l}\text { (b) Differences in } \\
\text { teaching methods, } \\
\text { expectations \& values }\end{array}$ & $\begin{array}{l}\text { (c) Off campus } \\
\text { discrimination }\end{array}$ \\
\hline $\begin{array}{l}\text { (c) Importance of making } \\
\text { friends with English students }\end{array}$ & $\begin{array}{l}\text { (b) Difficulty taking part } \\
\text { in leisure activities }\end{array}$ & & \\
\hline
\end{tabular}

Notes: a. The 4 superordinate themes are indicated by a. $\left(a^{1}\right.$ and $a^{2}$ illustrates the connection between two of the superordinate themes); (b) Sub-themes unique to one superordinate theme indicated by (b); (c) Sub-themes shared between superordinate themes indicated by (c).

\section{Appendix C. Example of One Interview Coded Transcript (Participant 3)}

Annotated with examples of initial codes, themes and application of socio-cultural theory. Annotations are in bold.

I: Hi, I'm Georgia. As you know the aim of the research is to gain a deeper insight into what life is like for you as an international student, adapting and settling into learning and living in a different country. I am going to conduct a timeline interview which involves you freely talking about your experiences over the 3 year period starting with your initial transition, till now, in your final year. The interview will hopefully last for around 30/40 min. I will prompt you throughout the interview if you get stuck with what to say. Just to remind you that all information will remain confidential and pseudo names 
will be used to maintain anonymity. You don't have to mention anything you don't feel comfortable talking about and you have the right to withdraw your data during and after the study. If you could just read and sign this consent form here, please. Thank you.

P: Er, okay.

I: Do you have any questions?

P: No thank you.

P: Ok, so I moved here two years ago from South Korea. To come to England I have to have a British Visa which costs $£ 1000$ and then we need a minimum IELT score of 5.5, overall score 6 or 6.5 , which is very difficult. I wanted to study in London, in the big universities, but I couldn't because I only scored 5.5 and they don't accept that. So I thought about how I could get into a University in the UK and I sent an email to all of the Universities and they say that if you don't have 6 or over then we can't let you in (Certain level of English speaking skills required to attend uni). But I found Huddersfield, and they said that if you have 5.5 IELT you can start at Huddersfield University if you complete an English course for a month. I think Huddersfield was a good choice because they really support international students; they gave me scholarship of $£ 2000$ (Huddersfield has a lower entry level and provide funding so they support international students). So er, when I first moved to Huddersfield it was really really terrible memories. (Terrible memories of first moving to Huddersfield) because I had to do an English course to get into University, so I had to move to Huddersfield in the summer and they didn't class me as a University student because I hadn't started University yet. I didn't know this when I came and I didn't pay council tax but I already paid the whole of my rent fee. So when I was ready to move to the new property, they said that you never owned this house because you are not a University student. So this was very hard and difficult for me and I couldn't stop crying because I didn't know what was going on and I didn't understand anything (Complications due to lack of understanding of government polices language barrier (macro)). Erm also, during my first couple of days, black skinned people were following me and saying are you Korean? I want to know your phone number, do you have a boyfriend? And it was very shocking and very terrible and I was very scared. So at the time when I first moved here I thought that Huddersfield the city is very dangerous and British people looked very scary, a bit sheek and cruel. I didn't feel safe here and I wanted to go home. (Doesn't feel safe in her new environment due to harassment) I told my family I wanted to go home but they made me stay. They say I have to go to University to get a good job in big companies like Samsung. Everyone in South Korea is competing to be in big companies like that, and my parents are very strict, they want me to achieve (Strict family expectations due to competitive South Korean culture (macro)). I also didn't like it in my first few weeks because sometimes people think all Asian people are Chinese, but I think I understand other Western people cannot distinguish Asian people and which country they come from, cause I think at the time this was very rude because I am not Chinese (Discrimination/lack of cultural awareness from English people causes negative emotions (macro)). And when I told people I was from Korea, even when I say South Korea, they start asking me aw, are you North Korean? But I am not the same as North Korean. Every time they say, they say do you know North Korean president? Every time they ask me about North Korea I find it very difficult, it is a sensitive problem and it upsets me. So I didn't really speak to much people from the UK at first, I thought they were rude some of them and they didn't like me (Discrimination leading to negative views of British people).

\section{I: What was it like starting at the University?}

P: Erm, so I passed my English course and then started University. I was so scared to start because the British accent is so difficult and I was scared that I wouldn't understand anyone and wouldn't know what to do. Class was quite scary. In first year I was really timid in class, especially when we did group work. English is so difficult because even though I can understand and I thought about what grammar is incorrect and correct, when you actually try and communicate (Difficulties 
communicating due to lack of English speaking skills (macro)) in English you don't have enough time to think and work out what the person is saying so it becomes hard to communicate (Difficulties understanding English accent (macro)). Already the question has passed before I can work out how to answer, and then my friend starts talking about something else, so I don't really say anything. This was really hard and I think it affected my work academically in class (Lack of English speaking skills negatively affecting academic progress) because I didn't want to say anything in the first year in case I said it was wrong and people would start laughing. I didn't feel comfortable in class in my first few weeks because it was so different. In Korea we just sit and listen to what teachers say and we just write it down, there are no questions (Korean students listen and don't ask questions). As students always say 'teacher' before we ask a question, we always respect our teacher (Korean students have a lot of respect for their teacher. Culture differences in teaching (macro)) but when I say teacher I have a question here, other people start to laugh at me. I thought student's shouting out was very rude, but for British people its normal (Thinks English students shouting out is rude (change in macro-system affects quality of relationships in meso-system-doesn't connect to her new peers)). I find it hard to ask questions this way, so I prefer to stay quiet. In Korea if we get the answer wrong it's really bad, but in UK class British people just shout out even when they don't know the right answer. I found that we had to investigate and discuss the answers ourselves and this was hard, I struggled with my work because I didn't want to ask. I was scared to ask my tutor for help because I thought that he wouldn't be able to understand me and I wouldn't be able to understand him and I was scared the he might think I'm stupid, and the work was really hard, especially because I did it alone, even though in Korea we start with very hard grammar and I had to study English, but we never practised speaking so I was scared to ask for help (Scared of the tutor thinking she was stupid due to lack of understanding, meso-system is having a negative influence). In first year, erm I got a lot of work, essays and presentations in my work and at the time I had a lot of group meetings in lecture time but I didn't understand what to say because they said things very quickly and very fast and I didn't understand so I just listened and wrote notes (Difficulties becoming familiar with English teaching norms (shift in important macrosystem)). I was very clever in Korea but now I feel stupid because I don't understand everything as well as everyone else in my class, because I do not speak their language, and I struggle. My grades were not very good in first year. Whenever I attend my lecture time I come across as very timid, which made it very hard and I think it affected my progress at first. In first year I was really lonely, I didn't have a lot of friends (Shift in meso-system (no relationship with peers, no friends) having negative impact on her progress) and at the time I thought that many people were racists and they didn't really know me (Racism prevented her from re-building the important microsystem of friends) but now I've got to know some people it's okay. I communicated with my family and friends at home and at other Universities a lot and they make me feel better. I really wish to have lots of English friend to improve my language but it's hard to spend time together when they don't understand me speaking, but they just sit in their own group in class, it's like Asian group, British group and other countries Peers interact with their own ethnic group making it difficult to make friends with domestic students, even non-white students. Cultural identity (macrosystem) cascades to micro-system preventing meso-system interactions. So this was hard at first. Erm, I did join a South Korean society so I could find some friends and this was the best thing. Before I met my friends from Korea I didn't really go out because I was scared of how to ask for things. I remember when I first came and I went to a restaurant and I ordered steak, fillet steak, and they didn't understand me so I had to write it down. I have to write everything down wherever I go. People often get angry or laugh and mock my accent, so it put me off going out unless I really needed to for a while. But now, when I'm with other people it's not so bad and I have practised what to say.

I: Do you feel like making friends with people from South Korea helped you then?

P: It helps because I can speak in my own language and they are from the same culture so they don't find things I do weird and I can find friends that are going through the same thing as me 
(Shared cultural identity with Korean students (macro) and domestic students interested in her culture helps. Problems she experiences dissipate, as there is no discrimination/racism preventing her from socializing and re-building important micro-system). Because if I was on my own I think I would just want to go home because it's so hard. The society was really good for me because we have our meetings with other international and British people and the people are very interested in Korean culture so we teach Korean and they teach me about English culture and this really helps me (Speaking and socialising with culturally similar people helps (macro, allowing her to re-build important micro-systems). New peers (microsystem) develop her knowledge of British culture allowing her to learn and adjust to the new macro-system). I think if I live in London or Manchester, they have a lot of Korean food and Korean restaurants but in Huddersfield there are not any Korea restaurants or stores. When I feel tired or ill we usually eat a certain soup and rice but here I cannot buy it or any Korean stuff so I ate hamburger, this makes me feel really sad and homesick. In Korea we have lots of different types of medicine but here people just take medicine all in one. So when I feel a bit tired or ill it does make me want to go home with my family.

I: Yeah. So joining the society really helped you then?

P: Yeah it did but erm in second year it was still hard because I still didn't have very good language but I had lived here for a year so I was not as timid anymore, I tried to communicate with more English people to improve my English. In first year my class mates think I'm timid and I am Asian and I can't speak English but now we talk a little bit in class in group work, but they still sit in their own groups so we don't talk a lot (Slow improvement in interaction with peers (meso-system) but still major divisions of class groupings meaning the meso-system interactions are limited). I really wish to have lots of English friends because of my language but it's hard a lot and spend time together when they don't understand me speaking. Erm I felt a lot more supported because British people in my class would help me during presentations, when we did group work now, and that was nice. I still have a lot of problems academically (Group work helped make her feel more supported as it allowed for interaction with peers, quality of interactions (meso-system) is slowly improving. Academic problems still there but more confident in asking for help (meso-system, interaction with tutor is improving)). In first year I can't say anything or ask for help in my tutor but in second year I felt a bit more confident and I could ask for help. It was a very big change. I also became Vice president of my society and I started to help plan events and this also gave me confidence on campus. I spoke to a lot more people and people from different countries and I was really interested getting to know people and their backgrounds. I started to learn a lot more about English culture but things were still a bit strange for me.

\section{I: Strange for you how? Could you elaborate on this?}

P: Well erm, In Korea when you go to restaurant we really like sharing food. So British people really like a pizza so we went bar maroc and we thought, oh we're very hungry so we'll buy a pizza. Okay, do we need to buy two pizza and they're like what we're sharing? But I was like I can't eat a whole pizza, and they thought it was very weird because they just eat the whole pizza, but we never do that. There are so many different things and it's hard to know what's right and wrong behaviour and I'm so timid, I don't want to do wrong behaviour. Cultural differences in everyday activity of eating. Worries about right and wrong behaviour. Also, In Korea, going out for food was our main social activity, we would always meet up for food or even if we went for a drink we would order soup and fruit and we sit there and everyone talks. But I don't really like the food here so we don't go out much and there's not really much else to do, I miss it. British people also they just stand drinking (Domestic students interests not appealing to her as a party scene does not allow for personal interaction with peers) so you know it was very hard because we wanted to just sit and talk but we had to go around stand and the music is too loud which I think it's hard to meet new people (Lack of shared interests preventing interaction with peers (culturally different ways of socializing, macrosystem cascades 
to affect microsystem layer)). Although I found that some British people are nice, some were still racist. Erm, a few weeks ago one Korea guy, one Hong Kong guy and one British, three guys went to KFC they were just eating hamburger and talking about something, but other teenager British girls started throwing chips, so racism is a big thing. The British guy got angry so they smashed his coffee. The teenager just wanted to fight and the British guy tried to stop it, and they were like Asian Asian Asian and it was terrible, but that's only some times (Still experiencing and exposed to racist behaviour; shift in macrosystem means the individual experiences discrimination). A lot of people are nice but a few people are terrible. On Christmas day I also worked with my friend in front of McDonalds some people crushed egg on my shoes. I've experienced this all throughout living here. It really upsets me (Discrimination is constant, a frequent negative experience resulting in psychological distress).

I: So discrimination is a big thing for you?

P: Yeah.

P: I find that I have started to do some English things now and they feel more erm, normal ((laughs)). But first, In Korea, University girls put on high heels everyday but British girls they only wear flat shoes. People started to ask why you wear these shoes every day, and they thought it was weird, so I started to wear flat shoes too. (Difference between her, peers dress, and the accessories they use. Changes it to fit in with English peers; adopts 'rituals' of new community). Erm, and when it rains in Korea, we have to bring out an umbrella and if I didn't bring an umbrella out on a rainy day people would think, aw you're so poor, umbrella is very cheap, but you didn't bring umbrella? But in UK many people don't use umbrellas but every time it's a rainy day I bring my umbrella but my umbrella over here always breaks, so now I don't bring my umbrella but that feels very weird at first but now not so much now. But when I tell people they think it's so strange, so many people don't know our culture (Being forced to follow new culture, peers fail to provide acceptance of cultural differences). I also still have some problems. I'm still living in my property in my house but in summer I will be moving in another place. One week ago I had a problem because I already paid my rental fee $£ 2078$ but when I worked out one day I checked my bank account but they took a direct debit of $£ 2078$ also. So I woke up and washed my face and went to my agency and they say they cannot check that I paid my fee twice (Doesn't know how institutions work so she gets fobbed off). So I needed to go bank and they checked that I paid twice but then they sent me back to agency. I'm not stupid, but I can't do anything. So I go to bank and then I go to agency and then I go to bank and I go to agency and it's just so hard, the barrier between our understanding. However, I feel like I get a lot of support from the University now. I applied for jobs with my friend and no one responded, it's hard to find a job for me. But in Huddersfield University they support our internship, our placement (University supports individual allowing progress in areas like work experience). It was difficult because I need to write down my application and call other company, so it's good that they can sort that for us so we can get some experience in work. I think it would be hard to get experience otherwise for me (Worries that she won't get a job as it's difficult to find a job in the UK (this would have been exo if analysed)). Having no job isn't too bad because my parents send money over to me so I can pay for everything; they want me to do well Parents send money so major source of financial support. Sometimes I still miss being in my country because in Korea the weather is very sunny so it's normally Korean personality that they are very active and they really like a beer. But English weather is always gloomy, with short day light times, so they just want to stay in house and read a book after Uni (Difference in interaction with peers (meso-system interactions) inhibiting interaction). In Korea, I already graduated in Korea, so when we finished class we go to pub for a coffee to communicate with each other but in the UK with British people, even though we finished our lecture, they just went home. They didn't communicate or socialise. So before I started in the UK I thought it would be very similar to Korean university society but British people are very different (Part of the culture shock was her 
belief that university would be similar to her home country. Cultural shock in part occurs due to incorrect perception of macrosystem). I think maybe because British weather is so rainy and gloomy.

I: Yeah.

I: Yeah.

P: I do hope to stay in UK when I graduate. After uni if I can I want to work in the UK, I don't want to go back to Korea because I really want to get experience in other country. But I know it is very difficult to get a job in the UK. I worry a lot that I won't get a job.

I: What is third year like for you?

P: Oh third year is better. I like the group work now I've learnt how to discuss my answers. I like discussing the answers with my class mates, I realised that it's okay to be wrong here. I have a British friend which is good, so I started to learn more about British culture and she also helps me with my language when we are out. She is from Manchester so I've started to explore Manchester and I sometimes go with my Korean friends too, because we can eat nice food there and it's so lively and there are nice clothes shops and we can sit and talk in more places and have a drink, it's really good. I wish I would have gone earlier. Manchester really helps when I'm homesick, I go to the restaurants and eat my home food with my friends and I feel better. Also, Korean people really think about our future we have to get a job and we have to make a lot of money Being successful and earning money is valued in Korea but during my stay in UK it is very surprising for me that happiness isn't to make a lot of money (Korean focused on money, English focused on happiness). You have a very different perspective. When I speak to my British friend she told me that if they graduate this university, even though she just worked in café, if that makes her happy then that is okay, she can do that and be happy but in Korea we have to work in big companies like Samsung, you have to so everything is about studying, your family expect you to do well. If you don't do well it is frowned upon and you are not happy. English speaking is very valued in Korea; there is a lot of money in English speaking. Although my English still isn't great I have more confidence going to cafes for example, and asking for what I want on my own now, it's good. I think it was also harder for me because my friend in America University, even though they study English it's so different. They say aw lovely your English is so good to her, but British people, even though I speak English they're like oh no you need to study English, your English isn't good because your pronouncing is so different because I pronounce it like American English, I didn't think it was such a big difference. (Strong emphasis on accent, knowledge of language itself not enough). So I think it was easier for my friend. Pronunciation is very hard, but I think if I stay here longer and start to meet more people, it will get better. I was so nervous doing this interview in case you didn't understand me ((laughs)). Erm, I think that's everything.

I: Have you got any questions? If you just want to look at the Debrief here.

P: No, thank you.

\section{References}

1. HESA (Higher Education Statistical Agency). Headline Statistics. Available online: http:/ /www.hesa.ac.uk (accessed on 1 October 2012).

2. Bronfenbrenner, U. The ecology of cognitive development: Research models and fugitive findings. In Development in Context: Acting and Thinking in Specific Environments; Cornell University: Ithaca, NY, USA, 1993; pp. 3-44.

3. Bronfenbrenner, U. The Ecology of Human Development: Experiments by Nature and Design; Harvard University Press: Cambridge, MA, USA; London, UK, 2009.

4. Fisher, S.; Bruce, $\mathrm{H}$. The stress of the transition to university: A longitudinal study of psychological disturbance, absent-mindedness and vulnerability to homesickness. Br. J. Psychol. 1987, 78, 425-441. [CrossRef] [PubMed] 
5. Leese, M. Bridging the gap: Supporting student transitions into higher education. J. Furth. High. Educ. 2010, 34, 239-251. [CrossRef]

6. Lowe, H.; Anthony, C. Mind the gap: Are students prepared for higher education? J. Furth. High. Educ. 2003, 27, 53-76. [CrossRef]

7. Cook, A.; Janet, L. Do Expectations Meet Reality? A survey of changes in first-year student opinion. J. Furth. High. Educ. 1999, 23, 157-171. [CrossRef]

8. Hechanova-Alampay, R.; Terry, A.B.; Neil, D.C.; Van Horn, R.K. Adjustment and strain among domestic and international student sojourners a longitudinal study. Sch. Psychol. Int. 2002, 23, 458-474. [CrossRef]

9. Andrade, M.S. International students in English-speaking universities: Adjustment factors. J. Res. Int. Educ. 2006, 5, 131-154. [CrossRef]

10. Lee, K.C. Tips for international students' success and adjustment. Int. Stud. Exp. J. 2014, 2, $13-16$.

11. Collings, R.; Swanson, V.; Watkins, R. Peer mentoring during the transition to university: Assessing the usage of a formal scheme within the UK. Stud. High. Educ. 2016, 41, 1995-2010. [CrossRef]

12. Chan, A.W. Mentoring ethnic minority, pre-doctoral students: An analysis of key mentor practices. Mentor. Tutor. Partnersh. Learn. 2008, 16, 263-277. [CrossRef]

13. Huang, R. Mapping Educational Tourists' Experience in the UK: Understanding international students. Third World Q. 2008, 29, 1003-1020. [CrossRef]

14. Elliot, D.L.; Reid, K.; Baumfield, V. Beyond the amusement, puzzlement and challenges: An enquiry into international students' academic acculturation. Stud. High. Educ. 2016, 41, 2198-2217. [CrossRef]

15. Hofstede, G.; Gert, J.H.; Michael, M. Cultures and Organizations: Software of the Mind; McGraw-Hill: London, UK, 1991.

16. Liu, L. An international graduate student's ESL learning experience beyond the classroom. TESL Can. J. 2012, 29, 77-92. [CrossRef]

17. Durkin, K. The adaptation of East Asian masters students to western norms of critical thinking and argumentation in the UK. Intercult. Educ. 2008, 19, 15-27. [CrossRef]

18. Poyrazli, S.; Philip, R.K.; Adria, B.; Al-Timimi, N. Social support and demographic correlates of acculturative stress in international students. J. Coll. Couns. 2004, 7, 73-83. [CrossRef]

19. Pedersen, P.B. Counseling international students. Couns. Psychol. 1991, 19, 10-58. [CrossRef]

20. Yeh, C.J.; Mayuko, I. International students' reported English fluency, social support satisfaction, and social connectedness as predictors of acculturative stress. Couns. Psychol. Q. 2003, 16, 15-28. [CrossRef]

21. Constantine, M.G.; Okazaki, S.; Utsey, S.O. Self-concealment, social self-efficacy, acculturative stress, and depression in African, Asian, and Latin American international college students. Am. J. Orthopsychiat. 2004, 74, 230. [CrossRef] [PubMed]

22. McCullough, J. Asian foreign students in japan-A look at their problems and views. J. Inst. Asian Stud. 1988, 15, 141-160. (In Japanese)

23. Lin, C.-H. The Relationship of Racial Identity, Psychological Adjustment, and Social Capital, and Their Effects on Academic Outcomes of Taiwanese Aboriginal Five-Year Junior College Students; ProQuest: Cambridge, UK, 2008.

24. Denicolo, P.; Pope, M. Adults learning-Teachers thinking. In Insights into Teachers' Thinking and Practice; Psychology Press: East Sussex, UK, 1990; pp. 155-169.

25. Goodson, I.F.; Sikes, P.J. Life History Research in Educational Settings: Learning from Lives; Open University Press: Milton Keynes, UK, 2001.

26. Adriansen, H.K. Timeline interviews: A tool for conducting life history research. Qual. Stud. 2012, 3, 40-55.

27. Baron, R.A.; Byrne, D. Social Psychology: With Research Navigator. In International, with Research Navigator; Pearson/Allyn and Bacon: Boston, MA, USA; London, UK, 2004.

28. Cabaroglu, N.; Denicolo, P.M. Exploring student teacher belief development: An alternative constructivist technique, snake interviews, exemplified and evaluated. Pers. Constr. Theory Pract. 2008, 5, $28-40$.

29. Braun, V.; Clarke, V. Using thematic analysis in psychology. Qual. Res. Psychol. 2006, 3, 77-101. [CrossRef]

30. Poyrazli, S.; Grahame, K.M. Barriers to adjustment: Needs of international students within a semi-urban campus community. J. Instr. Psychol. 2007, 34, 28-46.

31. Barrera, M. Models of social support and life stress: Beyond the buffering hypothesis. In Life Events and Psychological Functioning: Theoretical and Methodological Issues; Sage: Newbury Park, CA, USA, 1988; pp. 211-236. 
32. Ikeguchi, C. Internationalization of Education \& Culture Adjustment. The Case of Chinese Students in Japan. Intercult. Commun. Stud. 2012, 21, 170-184.

33. Kao, C.; Gansneder, B. An assessment of class participation by international graduate students. J. Coll. Stud. Dev. 1995, 36, 132-140.

34. Sawir, E.; Marginson, S.; Forbes-Mewett, H.; Nyland, C.; Ramia, G. International student security and English language proficiency. J. Stud. Int. Educ. 2012, 16, 434-454. [CrossRef]

35. Baier, S.T. International Students: Culture Shock and Adaptation to the US Culture; Eastern Michigan University: Ypsilanti, MI, USA, 2005.

36. Brown, L. The role of food in the adjustment journey of international students. In The New Cultures of Food: Marketing Opportunities from Ethnic, Religious, and Cultural Diversity; Gower: London, UK, 2009; pp. 37-53.

37. Locher, J.L.; Yoels, W.C.; Maurer, D.; Van Ells, J. Comfort foods: An exploratory journey into the social and emotional significance of food. Food Foodways 2005, 13, 273-297. [CrossRef]

38. Wong, J.K.-K. Are the Learning Styles of Asian International Students Culturally or Contextually Based? Int. Educ. J. 2004, 4, 154-166.

39. Nguyen, P.-M.; Terlouw, C.; Pilot, A. Culturally appropriate pedagogy: The case of group learning in a Confucian Heritage Culture context. Intercult. Educ. 2006, 17, 1-19. [CrossRef]

(C) 2017 by the authors. Licensee MDPI, Basel, Switzerland. This article is an open access article distributed under the terms and conditions of the Creative Commons Attribution (CC BY) license (http:/ / creativecommons.org/licenses/by/4.0/). 